IJQRM

36,9

\section{4}

Received 24 September 2017 Revised 2 May 2018

8 October 2018

2 March 2019

Accepted 6 March 2019

\title{
RELIABILITY PAPER Reliability engineering application to pipeline design
}

\author{
Olanrewaju Ayobami Omoya \\ School of Mechanical, Aerospace and Civil Engineering, \\ The University of Manchester, Manchester, UK \\ Kassandra A. Papadopoulou \\ Alliance Manchester Business School, \\ The University of Manchester, Manchester, UK, and \\ Eric Lou \\ School of Engineering, Manchester Metropolitan University, Manchester, UK
}

\begin{abstract}
Purpose - The purpose of this paper is to investigate the application of reliability engineering to oil and gas $(O \& G)$ pipeline systems with the aim of identifying means through which reliability engineering can be used to improve pipeline integrity, specifically with regard to man-made incidents (e.g. material/weld/equipment failure, corrosion, incorrect operation and excavation damages).

Design/methodology/approach - A literature review was carried out on the application of reliability tools to $O \& G$ pipeline systems and four case studies are presented as examples of how reliability engineering can help to improve pipeline integrity. The scope of the paper is narrowed to four stages of the pipeline life cycle; the decommissioning stage is not part of this research. A survey was also carried out using a questionnaire to check the level of application of reliability tools in the O\&G industry.

Findings - Data from survey and literature show that a reliability-centred approach can be applied and will improve pipeline reliability where applied; however, there are several hindrances to the effective application of reliability tools, the current methods are time based and focus mainly on design against failure rather than design for reliability.

Research limitations/implications - The tools identified do not cover the decommissioning of the pipeline system. Research validation sample size can be broadened to include more pipeline stakeholders/ professionals. Pipeline integrity management systems are proprietary information and permission is required from stakeholders to do a detailed practical study.

Originality/value - This paper proposes the minimum applied reliability tools for application during the design, operation and maintenance phases targeted at the $O \& G$ industry. Critically, this paper provides a case for an integrated approach to applying reliability and maintenance tools that are required to reduce pipeline failure incidents in the $O \& G$ industry.
\end{abstract}

Keywords Oil and gas, Failure-centred design, Pipeline integrity, Pipelines, Reliability-centred design, Reliability-centred maintenance

Paper type Research paper

\section{Introduction}

Background: importance of pipelines

The world has over $2.5 \mathrm{~m} \mathrm{~km}$ of oil and gas $(\mathrm{O} \& \mathrm{G})$ pipeline with several key routes transporting various products (CIA, 2017); amongst these are O\&G products that are

(C) Olanrewaju Ayobami Omoya, Kassandra A. Papadopoulou and Eric Lou. Published by Emerald Publishing Limited. This article is published under the Creative Commons Attribution (CC BY 4.0) licence. Anyone may reproduce, distribute, translate and create derivative works of this article (for both commercial \& non-commercial purposes), subject to full attribution to the original publication and authors. The full terms of this licence may be seen at http://creativecommons.org/licences/by/4.0/legalcode

The authors declare that there is no conflict of interest. The authors received no financial support for the research, authorship and/or publication of this paper. The authors would like to acknowledge the individuals who took part in the survey.
International Journal of Quality \& Reliability Management Vol. 36 No. 9, 201 pp. 1644-1662 Emerald Publishing Limited 0265-671X DOI 10.1108/IJQRM-09-2017-0197 
transported between regions, countries and continents using these pipelines. The USA has over 2,000,000 km, Europe has over 400,000 km and Africa has around 50,000 km of pipelines. Consequently, with increasing energy demands around the world and with O\&G being the primary source of energy, pipelines are becoming increasingly important. The US Energy Information Administration's World Energy Outlook predicts a global liquid and natural gas consumption rise from about 55 to $80 \mathrm{bn}$ barrel of oil equivalent by 2050 as demonstrated in Figure 1 (Energy Information Administration (EIA), 2017). According to ExxonMobil's (2017) energy outlook forecasts, global demand for energy is expected to climb about 25 per cent by 2040 and would soar significantly higher - closer to a 100 per cent increase - but for anticipated efficiency gains across the economy. To support the growth in demand, pipeline infrastructure is anticipated to grow 7 per cent in the next 15 years, which translates to 8,000 $\mathrm{km} / \mathrm{year}$ and on an international level, $32,000 \mathrm{~km}$ of new pipelines are constructed annually with a value of $\$ 28 \mathrm{bn}$ (Hopkins, 2007). In the USA, there was a pipeline investment of $\$ 101 \mathrm{bn}$ between 2012 and 2016 and a capital expenditure of $\$ 2.3-\$ 3.7 \mathrm{bn}$ per year till 2035 is projected to meet energy demands (American Petroleum Institute, 2017).

\section{Background: pipeline failure}

However, the safety of $O \& G$ pipelines remains a sticky point due to the effect of pipeline failure on human life, the environment and other infrastructure. Figure 2 shows the effects of pipeline failure over the last 20 years in terms of fatalities and injuries in the USA alone. Figure 3 shows the monetary cost of these incidents in terms of the value of the properties damaged. From Pipeline and Hazardous Materials Safety Administration's (PHMSA) data, it can be concluded that pipeline integrity remains a critical issue because pipeline incidents cost an average of $\$ 414 \mathrm{~m}$ plus the fatalities and injuries due to its failure every year. More so, Europe had a total of 1,309 incidents between 1970 and 2013 for gas pipelines alone (European Gas Pipeline Incident Group, 2015).

Despite these short comings, O\&G pipelines remain the most efficient and effective mode of fluid transportation when compared with rail or road transport. Statistics from the CEPA (2014) shows that their network of pipelines transports an equivalent of 15,000 lorries and 4,200 rail cars in a day. From a safety aspect, pipelines remain the safest mode of transportation of $\mathrm{O} \& \mathrm{G}$ products, when comparing pipeline failure statistics with other

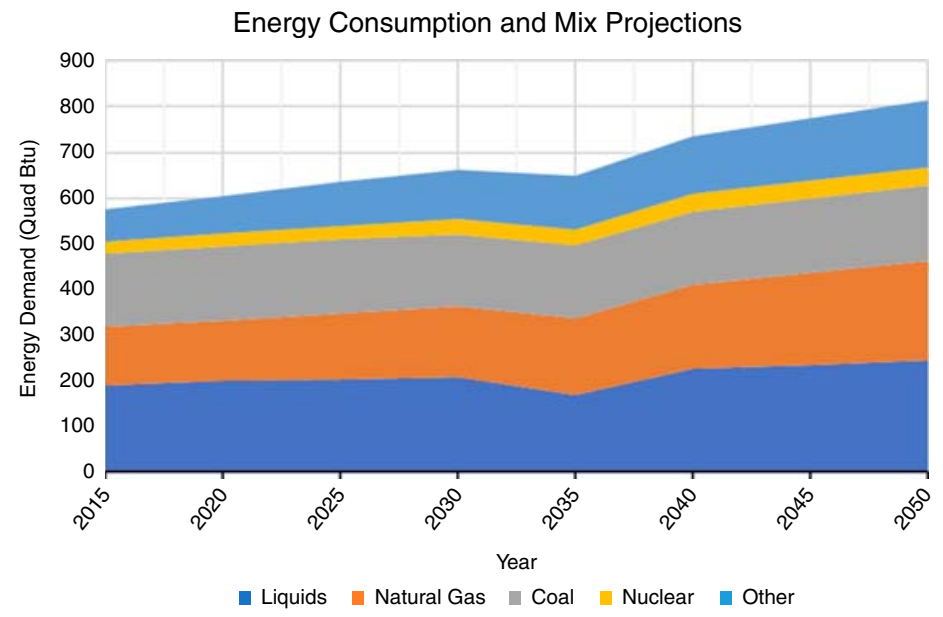

Source: EIA (2017)

\section{Reliability engineering application}

1645
Figure 1.

Energy demand forecast by source and the global energy mix 
IJQRM

36,9

\section{6}

Figure 2.

Trend for pipeline incidents from 1997 to 2016

Figure 3.

Cost of pipeline failure from 1997 to 2016

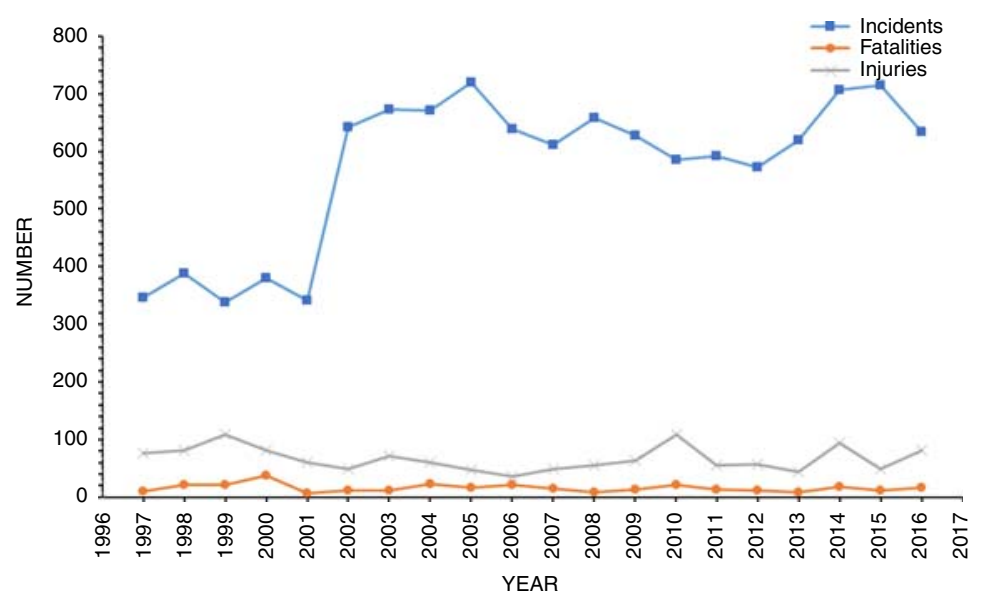

Source: PHMSA (2018)

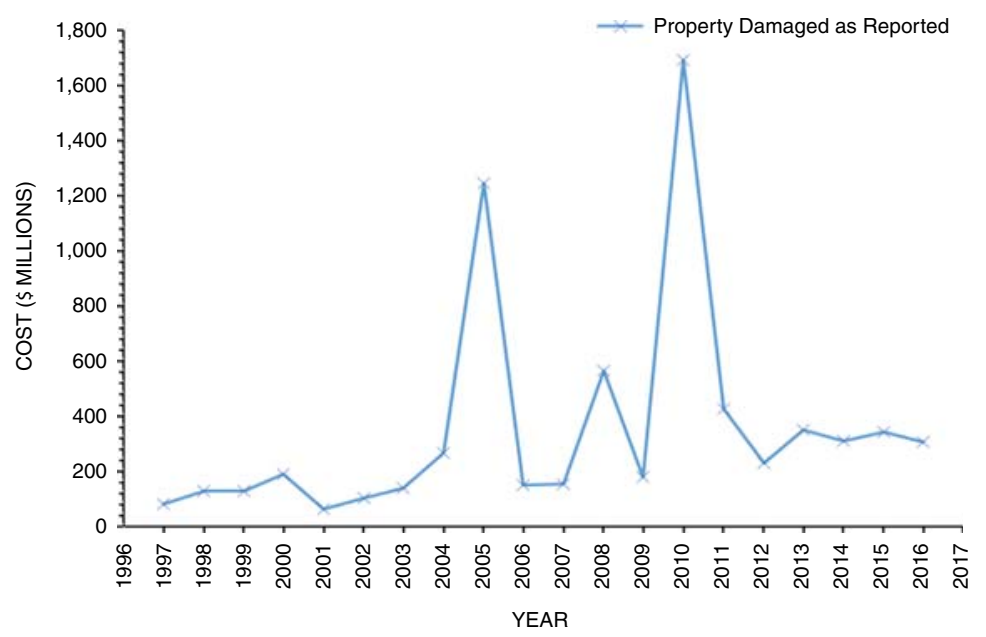

Source: PHMSA (2018)

modes of transportation of $O \& G$, it is shown that natural gas pipelines have an incident rate of 0.89 incidents per billion tonne-miles compared to road and railway which have a rate of 19.95 and 2.08, respectively (Furchtgott-Ruch, 2013).

Data from the USA show that more than 80 per cent of pipeline incidents are man-made (PHMSA, 2018). As seen in Figure 4, out of 11,761 pipeline incidents that happened between 1998 and 2017, only 18 per cent are due to natural causes and other unknown causes. The causes of failure include material/weld/equipment failure, corrosion, incorrect operation and excavation damages, which account for 33, 18, 8 and 15 per cent, respectively. This paper focusses on how these man-made forms of failure of O\&G pipeline systems can be prevented or reduced by applying reliability tools at different stages of the pipeline life cycle. 


\section{CAUSES OF PIPELINE INCIDENT: LAST 20 YEARS}
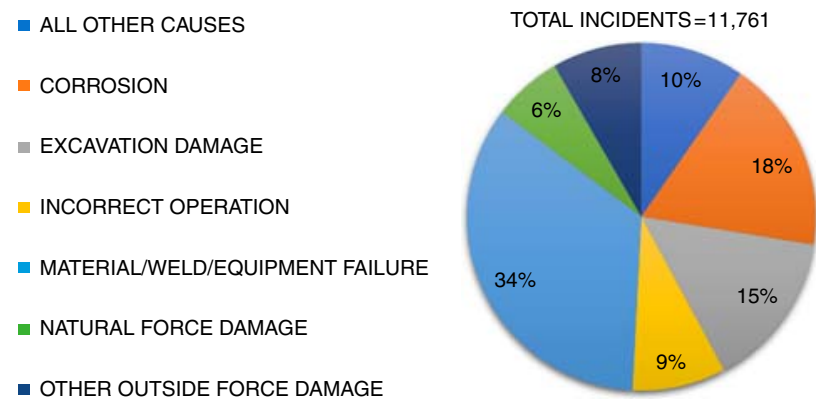

Source: PHMSA (2018)
Reliability engineering application

\section{7}

Figure 4.

Causes of pipeline incidents between 1998 and 2017

\section{Reliability engineering methods}

At this point, it is important to provide the definition of reliability which is "the probability that a system will perform its functions under certain environmental conditions over a specified period" (Andrews and Moss, 2002). Reliability engineering aims at developing methods and tools to predict, evaluate and improve the reliability, maintainability, availability and safety of a system (Birolini, 2007). It is a combination of reliability testing and data analysis, failure analysis and design for reliability (DFR) as illustrated in Figure 5 (Lau et al., 2004). Engineering design by reliability (EDBR) is a critical concept in design because it is at the design phase in the life of a product that the engineer can include features that will improve the reliability of a system (Kececioglu, 2003). Reliability-centred maintenance (RCM) (Moubray, 1997) also helps to maintain the reliability of the system above a certain reliability threshold.

\section{Reliability engineering tools for oil and gas pipelines}

There are several reliability tools that can be applied to O\&G pipeline systems (Birolini, 2007), it is an engineer's responsibility to understand each tool and how they can be applied to improve

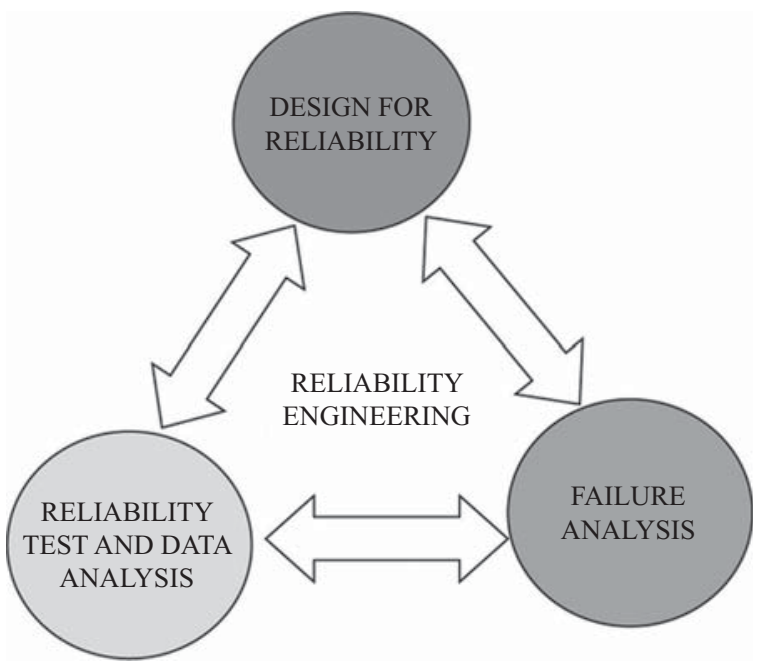

Source: Lau et al. (2004)

Figure 5. Illustration of reliability engineering approach 
IJQRM

36,9

\section{8}

Figure 6.

Cost implication of reliability the reliability of a product. Ossai (2013) uses life data analysis (Monte Carlo simulation) to predict the time to failure for corroded pipelines, Ahmed et al. (2016) propose the use reliability block diagrams to improve the accuracy of Monte Carlo simulation, Petrovskiy et al. (2015) propose the application of failure mode effect and criticality analysis (FMEA and FMECA) for identifying both risks and hazards, hazard operability analysis (HAZOP) and hazard identification (HAZID) are applied across several industries including O\&G and Anjumna et al. (2012) propose the use of fuzzy logic along with bow tie analysis, Abaqus and other software tools are used as simulation tools, non-destructive testing (NDT) techniques are used for accelerated testing and measurement, structural reliability assessment is used to determine the structural reliability of a pipeline system in DNV codes and other pipeline codes. Other tools include root cause analysis (RCA), failure reporting, analysis and corrective action systems (FRACAS), to mention a few.

\section{Reliability optimisation}

Applying these tools comes at a cost to the system; this means that the engineer must find the optimal solution between designs based on performance, cost, safety and maintainability of pipeline systems. Figure 6 shows the relationship between reliability and cost; the initial cost of a product increases with increasing reliability but the post-implementation cost decreases with increasing reliability. In other words, a product with both low and high reliability will have a high total cost because either the initial cost or post-implementation cost will be too high. Mathematically, this relationship is shown in the two cases below:

Case 1: Low reliability $\rightarrow$ Low initial cost $\rightarrow$ High post - implementation cost,

Case 2: High reliability $\rightarrow$ High initial cost $\rightarrow$ Low post - implementation cost.

Therefore, the optimal solution between cost and reliability will be at the lowest point on the total cost curve; the optimum reliability is therefore not necessarily the highest achievable reliability but a balance of cost and reliability, finding the optimum reliability for the system which combines the multiple objectives of design (design, performance, safety and maintainability).

\section{Methodology}

The methodology used in this paper has two main parts; initially by collecting secondary data in a form of a literature review (see Figure 7), then by collecting primary data through a questionnaire format.

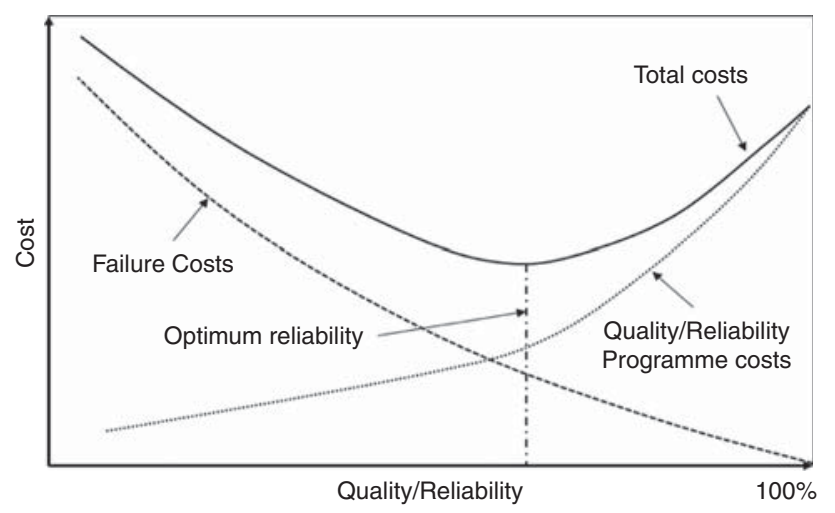

Source: O'Connor and Kleyner (2012) 


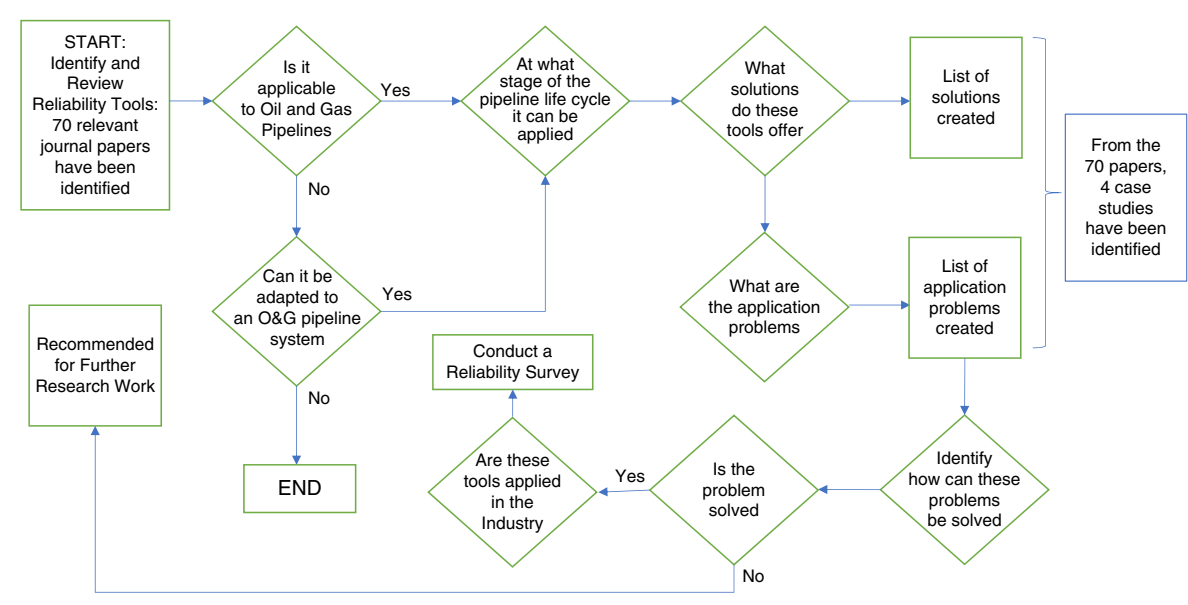

Reliability engineering application

1649

The literature review consisted of initially reviewing a literature of 70 papers in the theme of reliability tools applied to O\&G pipeline systems. Data from the PHMSA were used for this paper to create graphs which would aid to identify the causes of pipeline failure that would be integrated with the findings from the questionnaire survey. The reliability tools were searched using the university online library and Google Scholar search engine with focus on keywords such as reliability, reliability engineering and reliability tools; these provided a broad range of results of the reliability engineering field. Then, a focus was drawn on reliability tools for $O \& G$ pipelines by combining the keywords above with "O\&G pipelines" (e.g. reliability tools for O\&G pipelines), from these a broad set of literature was obtained. Finally, four of some of the tools identified are discussed as case studies to show that reliability tools can be applied to the life cycle stages of design, operation and maintenance of pipeline systems. The methodology for reviewing the reliability tools is presented in Figure 7. In reviewing the literature, the following questions were asked:

- Is this tool applicable to O\&G pipelines?

- What stage of the life cycle can this be applied?

- What solutions do these tools proffer?

- What are the limitations of these models?

- What can be done to improve them?

From these, several issues were identified and recommended for further research work. As the research proceeded, the question of whether these tools where applied in the industry came to the fore. Following that, a survey in a format of questionnaire was used as a research instrument; the objective was to evaluate the level of application of reliability tools in the O\&G industry. The questionnaire was self-administered, i.e. it was designed to be completed by a participant without the researcher's intervention. The questionnaire was structured in a pre-formulated and pre-determined written set of questions. This was considered as an effective data collection mechanism as the researchers knew precisely what was required for the data collection. The questions were constructed in a manner to determine the level of application of reliability tools by the pipeline engineers. The first part of the survey consisted of demographic type of questions about the participants and their experience, then in the second part the questions focussed on findings from the review of literature about the subject matter and the problems associated with the application of 
IJQRM

36,9

1650

reliability tools to O\&G pipeline systems. The survey responses were obtained by contacting $\mathrm{O} \& \mathrm{G}$ engineers via e-mail, the survey responses further validate findings from the literature review and bring to fore certain issues with applying reliability tools to O\&G pipeline systems. The questionnaire was aimed at getting qualitative data about reliability engineering application to $\mathrm{O} \& \mathrm{G}$ pipelines. The questions were asked without providing options so that the participants draw on their own knowledge and experience about the subject matter; however, a list of reliability tools was provided for the responders to have an idea of what those reliability tools are; there are 11 questions aimed at pipeline design, operation and maintenance. The questionnaire is available in Appendix 1. Verification was conducted through qualitative interviews as it provides further context and explanation on the results. Experts were current pipeline designers and operators from various O\&G producing countries. The data were analysed by manual content analysis.

\section{Case studies review}

Four of the case studies reviewed are presented from a review of 70 academic papers, these case studies focus on the application of the FTA, reliability modelling and data analysis. The case studies point out the problems of reliability tools application and provide solutions to some of these problems showing the relevance of reliability tools to pipeline design, operation and maintenance.

\section{Case Study 1: the failure expansion tree (FET)}

The FET (Lin et al., 2014) aims to improve the traditional FTA methodology, which has been shown to have various application problems. The FET is built on six main principles, which are created to avoid the problems of the traditional FTA which includes subjectivity, mutually inclusive events (repetition of failure events at different levels) and collectively in-exhaustive failure events (exclusion of some possible failure events).

The FTA provides quantitative (ranking of failure events) and qualitative analysis (determining what basic events can lead to a top event) of a system. With a well-modelled FTA, an engineer can determine the root causes of failure and quantitatively determine which failure events are most likely to occur and thus focus on them during design with the aim of preventing them. The FET solves the problem of inexhaustible failure modes by accounting for events which cannot be identified as "other" failure modes, this occurs across several levels of the FET. This leaves room for the FET to be expanded to include such rare events which cannot be done with the traditional FTA. This ensures that every level of the FET is collectively exhaustive. In addition, it solves the problem of subjectivity of the traditional FTA. When multiple numbers of engineers are trying to build an FTA, they are most likely going to come up with multiple models of FTA for the same product or system. The FET solves this problem by focussing on the physics of failure; by doing this, the multiple numbers of engineers are likely to come up with the same FET because the physics of failure is the same across all levels. Furthermore, the FET solves this problem by making the events mutually exclusive; thus, at whatever level the event is on the FET, it will produce the same probability of occurrence (failure probability). This is not the case with the FTA where the failure probability for an event depends on the level of the event. A practical example is presented in the paper (Lin et al., 2014).

Grouping the pipelines under several phases (useful life, infant mortality and wear out) as used in the FET will help in understanding the cause of pipeline failure. An example is the analysis done by Azevedo (2007) in which the pipeline was said to have corroded because of the wrong selection of the insulation used in the pipeline, a problem of manufacturing classified under infant mortality.

The FET is a more effective tool than FTA because it focusses on the physics of failure; this ensures that considerable attention is given to the system itself rather than the method 
used in creating the system. Hence, an engineer can identify the possible failure modes of the system and is more objective. Also, it provides the advantage of being collectively exhaustive, mutually exclusive at all levels.

Case Study 2: the condition-based fault tree analysis (CBFTA)

The CBFTA is a special FTA that improves on the FTA by applying a condition monitoring (CM) system that makes it a design tool as well as an operation and maintenance tool. Figure 8 compares the CBFTA and the FTA. The tool was created by Shalev and Tiran (2007) and applied to a two-pump system. The tool updates reliability values for a system and calculates the residual life; this is done periodically to ensure reliability is above control limit. However, the first question is whether the tool can be applied to O\&G pipelines. The conditions stated for its application are as follows:

(1) the critical components failure is a step-by-step deterioration process, which can be divided into predefined recognisable stages;

(2) the detection of each stage is possible by using a measurement device and observation; and

(3) for each failure stage, the residual time to failure is definable.

The authors believe that the tool can be used because all these conditions are fulfilled by an $O \& G$ pipeline system. Pipeline systems are composed of several components and the failure of its components is responsible for most pipeline failures (PHMSA, 2018), corrosion is the second highest cause of pipeline failures. These modes of failure (equipment failure and corrosion) can be monitored to identify the step-by-step deterioration of the entire pipeline system and the detection of each stage of deterioration is possible by using measurement devices. The evaluation of the residual time to failure is also possible, as shown by Zhou (2010), where he evaluates the failure probabilities of a pipeline with corrosive defects. From this, the reliability of the pipeline system and the time before failure can be determined using textbook reliability methods.

Two things are key in the application of this tool, $\mathrm{CM}$ and predictive maintenance; these are the solutions applied to the FTA to form the CBFTA making it an applicable real-time operative system analysis (Shalev and Tiran, 2007). Furthermore, the CBFTA does not only help determine the reliability of the system but also helps to determine the optimal path for operation of the system with spare components as illustrated in the paper by Shalev and Tiran. This makes it both an operation and maintenance tool. The CBFTA combines the statistical data of the FTA and the CM data for reliability monitoring and control.

However, one of the biggest issues with $O \& G$ pipelines is their accessibility for $\mathrm{CM}$. This leaves design and operations engineers with the work of coming up with a list of variables which can be monitored and used to calculate the reliability of the pipeline system.

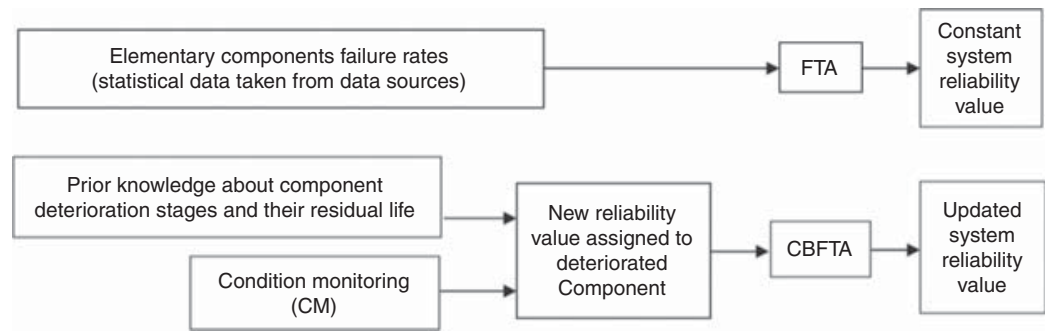

Reliability engineering application

Source: Shalev and Tiran (2007)

Figure 8.

Comparison of the CBFTA and the traditional FTA method 
IJQRM

36,9

1652

Shalev and Tiran (2007) provide an example of how this can be carried out on a two-pump system in their study. The problem of availability of historical data about a system for determining the failure probability of basic events of the FTA remains.

Case Study 3: reliability prediction tool, split system approach (SSA)

This tool predicts the reliability of a complex system by using a SSA, as reported by Sun et al. (2009). It identifies the complexity of pipeline system and solves the problem by applying the SSA, it also predicts the reliability of a pipeline system that has been maintained using preventive maintenance (PM). The model was created to solve the problems of reliability models that do not account for the complexity of a pipeline system and the impact of PM actions on system reliability (Sun et al., 2009). Some questions from the analysis of this case study are follows:

- Does the repair of the repaired part affect the unrepaired part of the pipeline?

- What is the methodology for determining the recovery coefficient?

- How is the reliability determined at any time, $T$, when there is no PM work carried out?

- What is the difference between time-based preventive maintenance (TBPM) and reliability-based preventive maintenance (RBPM)?

First, the exposed pipeline is assumed to be the only part that is preventively maintained in all PM actions and the reliability functions of the repaired pipes are assumed to be known (Sun et al., 2009). This is a limitation of this tool because it needs to be modified for cases when the buried part of the pipeline is repaired or both parts of the pipeline are repaired because at some point in the life of a pipeline, PM actions might need to be carried out on buried sections. However, the advantage of this tool is that it provides the SSA which distinguishes the repaired section from the unrepaired section of the pipeline system.

Another limiting assumption is that the failure of the repaired part is assumed to be independent of the unrepaired part (Sun et al., 2009). While the authors understand the need for this assumption in simplifying the model, this is not the case practically. The failure of a section of the pipeline will impact the reliability of the other sections of the pipeline, for example, a pressure increase due to failure of a section of the pipeline will increase stresses on the other sections which will affect the strength of that section and other conditions, hence the reliability. This is a problem because not knowing the reliability of the unrepaired section of the pipeline means that the reliability of the entire pipeline is assumed to be constant (Sun et al., 2009). This shows the importance of having $\mathrm{CM}$ methods for knowing the reliability of any pipeline section. However, knowing the reliability of the pipeline in operation remains one of the biggest issues of reliability engineering (Blanks, 1992). It should be noted that the analysis done by Sun et al. (2009) indicates that if the recovery factor is reduced to zero the entire pipeline was still in a state of imperfect repair. This makes the model a valid one because it is known that maintenance work never restores the pipeline to its original reliability, this means that repair work is always imperfect.

Another important point is that it can be applied to a system with a known reliability function. This must be determined during the design phase. This shows the importance of a reliability-centred approach to design; DFR and EDBR models are at the foundation of reliability engineering application in operation and maintenance. Hence, the SSA model can also be used in the design phase to give a realistic reliability of the system that takes the complexity of a pipeline system into account. It serves as a model that can help a designer as well as operation and maintenance personnel to accurately predict the reliability of the entire pipeline system and to determine what kind of PM strategies can be utilised to 
prolong the life of the pipeline. The application of the tool to a real-life system gives more credibility to it, the result of this shows that a RBPM strategy is more effective for pipeline maintenance when compared with TBPM.

\section{Reliability engineering application}

\section{Case Study 4: a system for corroded pipelines}

This case study presented the "system reliability for corroded pipelines", a suitable tool for brownfield engineering in O\&G pipelines (Zhou, 2010). Most issues of pipeline integrity and safety come from already existing pipelines because they are old designs in which improvements in pipeline design from failure analysis cannot be applied. It is a simulation tool. The initial size of the defects (e.g. a large initial defect size lowers the reliability in comparison to a small initial defect size), the defect growth rates and the spatial variability of the internal pressure were found to affect the reliability of the pipeline. Hence, in a brownfield system for a given pipeline with limited resources, this would provide a maintenance programme aiming at maintaining a minimum acceptable reliability level (PHMSA, 2018). This model proves that there are certain physical variables which can be monitored to determine the stages of deterioration of the pipeline system (a requirement of Case Study 2). Zhou (2010) applies this tool to an existing pipeline and finds the relationship between various variables. The failure probabilities gotten from the application of this tool can be used to determine the reliability of the entire pipeline system. One of the solutions this tool provides is that it is modelled for a small leak, rupture and large leak. This makes it versatile for different modes of failure known to pipelines.

Pipeline engineers and operators need a method for evaluating the reliability of an existing pipeline system. The corrosion of a pipeline system can only be slowed down but cannot be prevented, old pipelines have multiple defects and this tool will serve to help detect probability of failure, and hence a reliability threshold below which the pipeline should not be used. Combined with other tools presented in this paper, pipeline operators will be able to predict the reliability of the pipeline system and provide effective and efficient maintenance strategies which help to prevent pipeline failure.

The question for this tool is whether the pressure of the system is the only important variable in failure via leakage and rupture? Electrochemical properties of the system also affect the Time Needed before Action, i.e. the time before which maintenance work needs to be done. An improvement would be to include all possible variables which are affected with the fluid flow that could increase the rate at which the pipeline leaks or ruptures. Another improvement on this tool will be to find ways of determining the reliability of pipeline components which account for majority of pipeline failures. After this is done, it can be combined in a series or parallel system to determine the reliability of the entire pipeline system.

\section{Review and analysis}

When these four tools are combined, they cover the design, operation and maintenance of the pipeline. The FET (Case Study 1) can be applied at the design phase to determine the most critical failure event that is likely to occur with the help of risk ranking and focussing on it during design. Using the structure of the FET, the engineer identifies failure modes which need to be condition monitored during operation of the pipeline system which makes the CBFTA (Case Study 2) applicable by monitoring various stages of failure for the pipeline system. With this, the CBFTA becomes useful for operation and maintenance personnel because they can evaluate the reliability of the pipeline system at any given time and maintain the pipeline above a reliability threshold. Using the data collected, a modified form of the reliability prediction tool (Case Study 3) can be used to determine what the best maintenance strategy will be, the SSA model can also be used in design and operation to account for the complexity of the pipeline system and the most effective PM strategy. 
IJQRM

36,9

1654

The CBFTA also helps to determine the optimal operation path for the various components of the pipeline system and in the final stages of the life of the pipeline, the system for corroded pipelines (Case Study 4) can be used in evaluating the correct failure probabilities of the pipeline system that can be used to keep the reliability of the pipeline system above a specified control limit. Table I shows the relevance of each reliability tool at different stages in the life of the pipeline system. However, these tools do not cover the other stages such as installation and decommissioning of the pipeline system.

\section{Research validation}

From the research conducted, a set of questions to determine the level of application of reliability engineering to $O \& G$ pipeline systems within the industry while also focussing on some of the results of literature review were used for the survey. For example, the authors asked about time-based approach to pipeline maintenance vs reliability-based approach, DFR vs design against failure, the use of the FTA and other reliability applicability issues.

Research validation responses were obtained from individuals with different number of years of experience in the O\&G industry, ranging from 2 to 30 years who are presently working as pipeline designers and operators. Table II shows the details of the participants of the survey. This sample size is not exhaustive, but it gives some insight into industry perspective on the use of reliability tools for pipeline design, maintenance and operations.

In response to the survey, five participants identified fatigue as the most frequent failure mode, while 14 identify corrosion. However, data from PHMSA (2018) indicate that material, weld or equipment failure has the highest percentage of repeated failure causes followed by corrosion then excavation damage. All the engineers responded that reliability tools have a role to play in reducing pipeline failure, some of the reliability tools identified by the engineers to be in use for pipeline design and operation are life data analysis, FMECA, simulation, DOE, RCA, ECA, structural reliability analysis (SRA), FTA, RBD, Monte-Carlobased statistics, Bayesian models, risk-based tools, testing tools like radiography and ultrasonic testing.

Table I.

The model suggested depicts the minimal requirement for $O \& G$ pipeline design, construction and operation and maintenance stages, according to the study results

\begin{tabular}{|c|c|c|c|c|c|}
\hline \multirow[b]{2}{*}{ Reliability and maintenance methods } & \multirow[b]{2}{*}{ Acronym } & \multicolumn{4}{|c|}{ Pipeline life cycle } \\
\hline & & $\begin{array}{l}\text { Concept } \\
\text { design } \\
\text { stage }\end{array}$ & $\begin{array}{l}\text { Basic and } \\
\text { detailed } \\
\text { design stage }\end{array}$ & $\begin{array}{l}\text { Construction } \\
\text { stage }\end{array}$ & $\begin{array}{l}\text { Operation and } \\
\text { maintenance } \\
\text { stage }\end{array}$ \\
\hline Quantitative risk assessment & QRA & Essential & Essential & & \\
\hline hazard operability study & HAZOP & Essential & Essential & & Essential \\
\hline Hazard identification study & HAZID & Essential & Essential & & Essential \\
\hline $\begin{array}{l}\text { Failure mode effect and criticality } \\
\text { assessment }\end{array}$ & $\begin{array}{l}\text { FMEA/ } \\
\text { FMECA }\end{array}$ & Essential & Essential & & \\
\hline Fault tree analysis & FTA & & Essential & & \\
\hline Failure expansion tree & FET & & Essential & & \\
\hline Split system approach & SSA & & Essential & & Essential \\
\hline Accelerated testing and measurement & AT\&M & & Essential & & \\
\hline Simulation/Modelling & SIM & & Essential & & \\
\hline Structural reliability analysis & SRA & & Essential & Essential & \\
\hline Design of experiments & DOE & & Essential & & \\
\hline Condition-based fault tree analysis & CBFTA & & & & Essential \\
\hline Reliability-based preventive maintenance & RBPM & & & & Essential \\
\hline Engineering criticality assessment & ECA & & & Essential & Essential \\
\hline $\begin{array}{l}\text { Failure reporting, analysis, corrective } \\
\text { action system }\end{array}$ & FRACAS & & & & Essential \\
\hline
\end{tabular}




\begin{tabular}{|c|c|c|c|c|}
\hline & Function & Years of experience & Country of practice & R \\
\hline Participant 1 & Subsea mechanical and structural engineer & 2 & Nigeria & 0 \\
\hline Participant 2 & Senior pipeline engineer & 6 & Nigeria & \\
\hline Participant 3 & Flowline design engineer & 5 & Nigeria & \\
\hline Participant 4 & Senior subsea engineer & 6 & Nigeria & \\
\hline Participant 5 & Subsea pipeline engineer & 3 & Nigeria & \\
\hline Participant 6 & Project engineer & 16 & Nigeria & 1655 \\
\hline Participant 7 & Integrity management & 17 & Australia & \\
\hline Participant 8 & Instrument control planning engineer & 3 & Malaysia & \\
\hline Participant 9 & Mechanical engineer & 9 & Trinidad and Tobago & \\
\hline Participant 10 & Project superintendent & 3 & Indonesia & \\
\hline Participant 11 & Pipeline integrity and capacity engineer & 4 & Nigeria & \\
\hline Participant 12 & Reliability engineer & 3 & UK & \\
\hline Participant 13 & Senior facility engineer & 7 & Canada & \\
\hline Participant 14 & Senior facility engineer & 30 & Canada & \\
\hline Participant 15 & Senior mechanical engineer & 13 & Angola & \\
\hline Participant 16 & Lead commissioning engineer & 16 & Saudi Arabia/Canada & \\
\hline Participant 17 & Process control engineer & 22 & Saudi Arabia & \\
\hline Participant 18 & Maintenance division head & 13 & Saudi Arabia & Table II. \\
\hline Participant 19 & Turnaround Coordinator & 14 & Oman & Details of survey \\
\hline Participant 20 & Mechanical engineer & 15 & Australia & participar \\
\hline
\end{tabular}

The engineers identified different hindrances to the application of reliability tools. Four of them state little or no understanding of reliability methods, the lack of engineers with such technical skills or competency, locations of $O \& G$ pipeline systems, lack of reliable and representative data, inability to determine the failure mode and failure rate, cost and schedule restraints (downtime), legislative requirements, uncertainties in failure root causes and multiple factor contributions to failure. These responses suggest that reliability engineering is still in its infancy as an engineering genre within $\mathrm{O} \& \mathrm{G}$ and there is a lack of reliability engineers as a workforce which can push its application to O\&G pipeline systems. A participant identified legislation/policies as a problem and seven participants pointed out the problem of lack of reliable and representative data as a major hindrance.

The participants were divided on whether maintenance activities are reliability based or time based. While some participants apply reliability-based systems, legislative requirements are time based; this places a burden on operators to either confine themselves to the time-based system or combine both, which is not cost effective and leads to extended downtimes.

However, as shown in Case Study 3, it is evident that reliability-based maintenance is a preferred method because it reduces the number of maintenance actions that need to be carried out (hence reducing cost and maintenance disruption) and ensures the reliability of the system stays above a control limit. The participants mention that maintenance operations are based on the results of time-based CM systems such as intelligent pigging and remote operating vehicles surveys which are then used to determine a course of action for maintenance activities.

The participants agree that most of the deterioration of pipelines takes place in stages, though some point out that it depends on the operating philosophy and some cases where failure could be sudden and unexpected, e.g. if it is an external factor. An important point is the emphasis on CM tools by the engineers. This agrees with the point raised in Case Study 2 that CBFTA is applicable to O\&G pipelines.

Most of the participants agree there is some application of reliability tools like lateral buckling analysis, RAM studies, fatigue life assessment and SRAs in design activities; they also point out that design activities are largely based on requirements of industry codes and standards. 
IJQRM

36,9

1656

These codes and standards show that the activities are more failure centred than reliability centred; this is inferred from the fact that reliability-centred design, operation and maintenance systems should provide space for systems which make it possible to monitor the system reliability in real time. This is not a requirement set by the codes and standards, pipeline integrity management systems are at the discretion of the pipeline operator as pointed out earlier and minimum requirements follow a time-based criterion.

Finally, responses from the participants suggest that the FTA is not used in design, operation and maintenance as only ten participants identify the tool and three refer to it as a design tool, while eight others refer to it as a maintenance tool as opposed to a best practice scenario where it is used throughout the pipeline life cycle as seen in the CBFTA.

From all the survey responses, there is an indication that there is a gap in the application of reliability tools to the O\&G pipelines. While some tools are utilised, tools such as the FTA are not widely used in design and operation. By improving the application of the FTA and other reliability tools both quantitatively and qualitatively could significantly help to solve a significant number of pipeline reliability issues.

\section{Discussion}

From the literature review, survey results and validation process, it is evident that reliability engineering can help improve pipeline integrity. However, there are various problems that need to be solved first to make these tools much more effective. This section discusses significant factors that affect the application of the reliability engineering looking from other perspectives within the O\&G industry, and practical issues including the mathematical applicability of the reliability tools.

\section{Pipeline design, operation, maintenance and reliability tools}

Is the integrity of pipelines a design, operation or a maintenance issue? If pipeline failure occurs despite the application of reliability tools in design, does this make the failure of pipelines a maintenance and operation issue? These are questions that need to be answered. Are O\&G pipeline failures a result of poor design methods or bad maintenance or operational tools? Answers to these questions can help determine how reliability tools will be applied to each phase of the pipeline life cycle from design, to construction, to installation, to operation and to maintenance.

The results of survey and review of literature show that the design, maintenance and operation phases of the pipeline life cycle apply some reliability tools like the FMEA, FRACAS RCA, fatigue assessment, SRA and others. However, there are certain problems that affect the effective application of these tools which require further research work by all stakeholders.

First is the quality of data available (e.g. lack of reliable, accurate and representative data). Reliability tools and models require both historical and real-time data sets; historical data help in creating models which represent new and existing pipeline systems, while real-time data help to predict future failure events. The survey results show that getting these data is a problem because of the length, size as wells as conditions in which the pipeline functions and past practices which do not require collection of such data. In this case, reliability engineers need to use models that combine expert knowledge and other knowledge areas that have been applied to risk assessment models (Wei-Shing et al., 2015).

Furthermore, reliability models which are true representations of the pipeline system remain a questionable because they depend on reliable and representative data. There is a need to build standard approaches which can be used as minimum requirements for determination of reliability of any system that is generally accepted by stakeholders. In the reliability studies for lateral buckling of O\&G pipelines, this study is used to predict the probability of lateral buckling occurring in a pipeline. This method is accepted because 
there is a standard approach to determining the probability. This shows that the O\&G industry is open to methods which can improve the reliability of the systems despite the uncertainties if there is a standard approach (Beele and Denis, 2012).

Pipeline standards and codes focus on failure prevention, while there are few sections that try to add reliability concepts to complement them. Reliability engineering tools should be applied in an integrated manner throughout the lifetime of the pipeline with design methods and integrity management systems focussing on reliability going from DFR to EDBR to RCM till end of life; for example, DeSanctis et al. (2016) describe the integration of $\mathrm{RCM}$ methodology with RAM in the O\&G industry as an application with high priority level, also a reliability-based system is a much more effective strategy as shown from the results of Case Study 3 and the Time to Action can be determined with Case Study 4, tools like the CBFTA (Case Study 2) and the reliability prediction tool (Case Study 3) should be effective in detecting failure before they occur. A focus on failure prevention methods is analogous to treating in humans the symptoms without taking care of the cause of the disease. By focussing on the reliability of the system rather than solely on the known failure modes, reliability tools and models should be more effective in preventing the failure of the pipeline system.

Legislation is required to improve the application of reliability models to pipeline integrity management. The survey results show that reliability models are applied more in countries with such legislation, as most legislation still focus on a time-based approach to integrity management. However, the effectiveness of these models in reducing pipeline failure is another matter. Hence, it is recommended that reliability engineering is applied to pipelines the same way quality assurance and quality control methods have become the standard in the industry.

\section{Cost of reliability tools application}

One of the questions asked by pipeline operators and designers is: "What is the cost of these tools compared to the cost of the pipeline failure itself?" It is evident from Figure 9 (created based on PHMSA data) that the cost of failure of O\&G pipelines is very high. When reliability tools are applied effectively, they will be able to reduce the number of incidents and their costs (as pointed out earlier in Reliability optimisation section), the cost of a low reliability leads to the high post-implementation cost, of an average of over $\$ 414 \mathrm{~m}$ annually being lost as damage to property in the USA alone (PHMSA, 2018). Therefore, pipeline operators should be willing to take these measures into consideration. However, only appropriate standards and regulations that incorporate the use of reliability prediction and
- OTHER OUTSIDE FORCE DAMAGE

Source: PHMSA (2018)

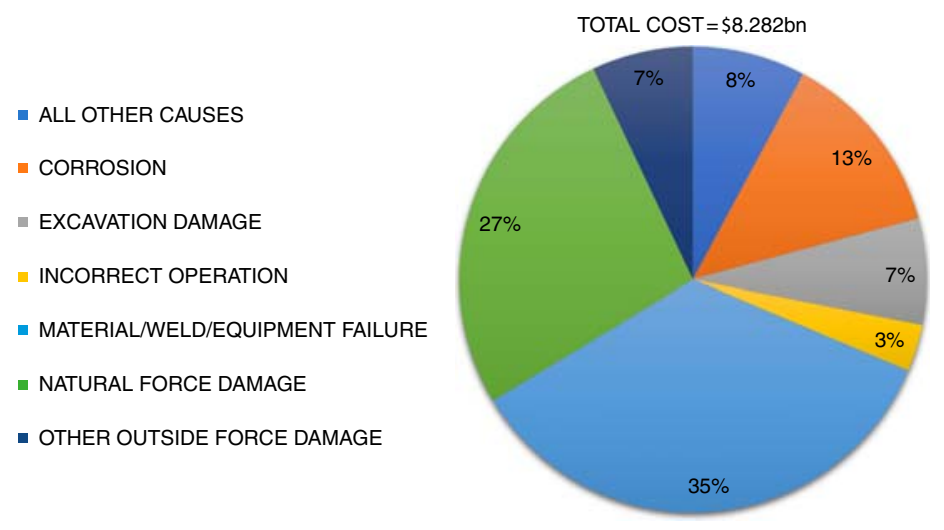

\section{Reliability engineering application}

1657
Figure 9.

Cost of pipeline damage by causes between 1998 and 2017 
IJQRM

36,9

1658

RCM tools will be able to ensure that pipeline designers and operators apply efficiently the reliability tools. A standard approach to reliability tools application needs to be developed for $O \& G$ pipeline application by regulators. An in-depth research is also recommended into the cost of applying reliability tools vs the cost of damages due to pipeline failure.

\section{Focussing on research for frequent failure modes}

As mentioned in the Introduction section, $O \& G$ pipelines are a crucial infrastructure to the energy industry, as there is a high dependency on this type of energy. Legislation set by countries and disruptive innovation in the area of technology is pushing for a move to different types of energy; however, the dependency now and in the next half century is deeply rooted in the $O \& G$ industry. The integrity of pipeline systems remains a challenge of pipelines, especially in brownfield engineering; already installed pipelines will continue to fail if engineers do not find ways to predict the reliability of these aged pipelines, the same errors will be repeated if pipeline design, operation and maintenance are not reliability centred.

Data from Figures 4 and 9 indicate that the focus of research should also be on corrosion, material/weld/equipment failure and third-party damage. Since corrosion cannot be eliminated, implementing reliability monitoring methods for pipelines that maintain reliability above reliability thresholds is necessary. Also, the integrity of equipment used in a pipeline system accounts for more than half of material/weld/equipment failure (PHMSA, 2018) and a focus should be put on their integrity. To be able to achieve this could be by developing DFR and reliability testing models for equipment which can be part of procurement requirements apart from current NDT methods.

\section{Conclusion}

In conclusion, while pipelines are an important infrastructure, improving data collection systems to develop reliability models which are a true representation of a pipeline system at various stages of the pipeline life is key. Developing a standard-integrated approach which is universally accepted as models that can be used during the entire pipeline system life cycle and serve as minimum requirements for pipeline reliability, creating legislation, standards and codes that focus on reliability as well as focussed research on the most frequent failure incidents should be the focus in improving pipeline integrity and reliability tools application.

\section{References}

Ahmed, W., Hasan, O., Tahar, S. and Hamdi, M.S. (2016), Formal Reliability Analysis of Oil and Gas Pipelines, Vol. 232, Sage Publishing, pp. 320-334.

American Petroleum Institute (2017), US Oil and Gas Infrstructure Investment through 2035, API, Washignton, DC.

Andrews, J.D. and Moss, T.R. (2002), Reliability and Risk Assessment, 2nd ed., Wiley-Blackwell, Hoboken, NJ.

Anjumna, S., Sadiq, R. and Tesfamariam, S. (2012), "Risk analysis for oil \& gas pipelines: a sustainability assessment approach using fuzzy based bow-tie analysis", Journal of Loss Prevention in Process Industries, Vol. 25 No. 3, pp. 505-523.

Azevedo, C. (2007), "Failure analysis of a crude oil pipeline", Engineering Failure Analysis, Vol. 14 No. 6 , pp. 978-994.

Beele, F.V.D. and Denis, R. (2012), "Numerical modelling and analysis for offshore pipeline design, installation and operation", Journal of Pipeline Integrity, Vol. 12 No. 4, pp. 273-286.

Birolini, A. (2007), Reliability Engineering, 7th ed., Springer.

Blanks, H. (1992), Reliability in Procurement and Use, Wiley, New York, NY.

CEPA (2014), "Why pipelines are needed?”, Canadian Energy Pipeline Association, Calgary, available at: www.cepa.com/about-pipelines/why-pipelines (accessed 30 March 2015). 
CIA (2017), The World Factbook, Central Intelligence Agency, Washington, DC.

DeSanctis, I., Paciarotti, C. and Oreste, D.G. (2016), "Integration between RCM and RAM: a case study", International Journal of Quality \& Reliability Management, Vol. 33 No. 6, pp. 852-880.

EIA (2017), International Energy Outlook, US Energy Information Administration, Washington, DC.

European Gas Pipeline Incident Group (2015), Gas Pipeline Incidents, EGIG, Groningen.

ExxonMobil (2017), The Outlook for Energy: A View to 2040, ExxonMobil, Irving, TX.

Furchtgott-Ruch, D. (2013), Pipelines are Safest for Transportation of Oil and Gas, The Manhattan Institute, Manhattan, NY.

Hopkins, P. (2007), "Oil and gas pipelines: yesterday and today", American Society of Mechanical Engineers, New York, NY, pp. 1-9.

Kececioglu, D. (2003), Robust Engineering Design by Reliability with Emphasis on Mechanical Components and Structural Reliability, DEStech Publications, Lancaster, PA.

Lau, J., Dauksher, W., Smetana, J., Horsley, R., Shangguan, D., Castello, T., Menis, I., Love, D. and Sullivan, B. (2004), "Design for lead-free solder joint reliability of high-density packages", Soldering \& Surface Mount Technology, Vol. 16 No. 1, pp. 12-26, available at: https://doi.org/ 10.1108/09540910410517013

Lin, J., Yuan, Y. and Zhang, M. (2014), "Improved FTA methodology and application to subsea pipeline reliability design”, PLoS One, March, Vol. 9 No. 3, available at: https://journals.plos.org/plosone/ article?id=10.1371/journal.pone.0093042

Moubray, J. (1997), Reliability Centred Maintenance (RCM), 2nd ed., Industrial Press.

O'Connor, P. and Kleyner, A. (2012), Practical Reliability Engineering, 5th ed., Wiley, Manchester.

Ossai, C.I. (2013), "Pipeline corrosion prediction and reliability analysis: a systematic approach with Monte Carlo simulation and degradation models", International Journal of Scientific and Technology Research, Vol. 2 No. 3.

Petrovskiy, E.A. et al. (2015), "FMEA-risk analysis of oil and gas process facilities with hazard assessment based on fuzzy logic", Canadian Center of Science and Education, Vol. 9 No. 5.

PHMSA (2018), “All reported pipeline incidents by cause”, Pipeline and Hazardous Materials Safety Administration, Washington, DC.

Shalev, D.M. and Tiran, J. (2007), "Condition based fault tree analysis (FTA): a new method for improved fault tree analysis (FTA), reliability and safety calculations", Reliability Engineering \& System Safety, Vol. 92 No. 9, pp. 1231-1241.

Sun, Y., Ma, L. and Morris, J. (2009), "A practical approach for reliability prediction of pipeline systems", European Journal of Operational Research, Vol. 198 No. 1, pp. 210-214.

Wu, W.-S., Yang, C.-F., Chang, J.-C., Châteaua, P.-A. and Chang, Y.-C. (2015), "Risk assessment by integrating interpretive structural modeling and Bayesian network, case of offshore pipeline project", Reliability Engineering and System Safety, Vol. 142, pp. 515-524.

Zhou, W. (2010), "System reliability of corroding pipelines", International Journal of Pressure Vessels and Piping, Vol. 87 No. 10, pp. 587-595.

\section{Further reading}

Energy Information Administration (EIA) (2013), Annual Energy Outlook, US Department of ENERGY, Washington, DC.

Ilaria De, S., Paciarotti, C. and Oreste, D.G. (2016), "Integration between RCM and RAM: a case study", International Journal of Quality \& Reliability Management, Vol. 33 No. 6, pp. 852-880.

McLinn, J. (2010), “A short history of reliability”, The $R \&$ M Engineering Journal, March, pp. 8-16.

Smith, D.J. (2011), Reliability, Maintenance and Risk: Practical Methods for Engineers, 8th ed., Elsevier, Oxford. 
IJQRM

36,9

1660

\section{Appendix 1: list of questions from the questionnaire used in this study}

Demographics and background of participant

Company Name:

Location:

Your Role/Function:

Years of Experience with Oil and Gas Pipeline Systems:

1. What do you think is the most frequent failure mode for oil and gas pipelines?

2. Do you think reliability tools can help reduce pipeline failure?

3. Are there reliability tools applied in pipeline operation and maintenance? (see list of some tools below), if yes please list some tools

4. What is the greatest hindrance to application of reliability tools to pipelines?

5. Are maintenance activities reliability based or time based?

6. If they are reliability based, please give a brief description of some of them?

7. Do design activities include reliability studies or are they solely failure prevention methods?

8. If there are reliability studies and analysis, please list some of them

9. Are there identifiable stages in the deterioration of pipelines or is it sudden?

10. Do design activities apply reliability tools? (see list of tools below), if yes please list of the tools

11. Do you use the FTA as a design tool or maintenance tool?

In the quantitative category, the typical tools are:

- Life Data Analysis (a.k.a. "Distribution Analysis" or "Weibull Analysis")

- Reliability Growth Analysis

- Accelerated Testing (a.k.a. "Life-Stress Analysis")

- System modelling using Reliability Block Diagrams (RBDs)

- Simulation

- Fault Tree Analysis (FTA)

- Design of Experiments (DOE)

- Standards-based Reliability Predictions (e.g. MIL-217)

In the qualitative category, the typical tools are:

- Failure Modes, Effects and Criticality Analysis (FMEA/FMECA)

- Reliability Centred Maintenance (RCM)

- Failure Reporting, Analysis and Corrective Action Systems (FRACAS)

- Root Cause Analysis (RCA)

\section{Appendix 2: references from original paper}

Antonio, C. and Nelson, F. (1999), "A fuzzy fault tree system for uncertainty analysis", Annals of Nuclear Energy, Vol. 26, pp. 523-532.

Atanassov, K. (1986), "Intuitionistic fuzzy sets", Fuzzy Sets and Systems, Vol. 20, pp. 87-96.

Azevedo, C. (2007), "Failure analysis of a crude oil pipeline", Engineering Failure Analysis, pp. 978-994. Azevedo, C. and Sinatora, A. (2004), "Failure analysis of a gas pipeline", Engineering Failure Analysis, pp. 387-400.

Biswas, R. (1997), “On Fuzzy sets and intuitionistic fuzzy sets”, NIFS, pp. 3-11.

Blanks, H. (1992), Reliability in Procurement and Use, New York, NY: Wiley.

Brown, R.E. (2004), Failure Rate Modelling Using Equipment Inspection Data, New York, NY, IEEE, pp. 693-700.

Bustince, H. and Burillo, P. (1996), "Vague sets are intuitionistic fuzzy sets", Fuzzy Sets and Systems, Vol. 79, pp. 403-405. 
Cai, K. (1996), "Fuzzy sets and systems", System Failure and Fuzzy Methodology: An Introductory Review, Vol. 83, pp. 113-133.

CEPA (2014), "Google chrome", available at: www.cepa.com/about-pipelines/why-pipelines (accessed 30 March 2014).

Cheng, S.-R., Lin, B., Hsu, B.-M. and Shu, M.-H. (2009), "Fault-tree analysis for liquefied natural gas terminal emergency shutdown system”, Expert System Applications, Vol. 36, pp. 11918-11924.

CIA (2013), The World Factbook, Washington, DC, CIA.

Condra, L. (1993), Reliability Improvement with design of Experiments, 2nd ed., New York, NY:

Reliability engineering application

Marcel Dekker.

Crawley, F., Lines, I. and J.Mather (2003), "Oil and gas pipeline failure modelling", Institution of Chemical Engineers, Vol. 81, No. Part B, January.

Dahlberg, E.P. and Bruno, T. (no date), Analysis of Gas Pipeline Failure.

De, S., Biswas, R. and Roy, A. (2001), "An application of intuitionistic fuzzy sets in medical diagnosis", Fuzzy Sets and Systems, Vol. 117, pp. 209-213.

Deus Rescue (2011), “The Deus Rescue blog”, available at: www.deusrescue.com/blog/post/2011/05/07/ the-difference-between-quality-and-reliability/ (accessed 15 July 2014).

Energy Information Administration (EIA) (2013), Annual Energy Outlook, Washington, DC, US Department of Energy.

European Gas Pipeline Incident Group (EGIG) (2011), Gas Pipeline Incident Report.

Furchtgott-Ruch, D. (2013), Pipelines are Safest for Transportation of Oil and Gas, Manhattan, NY.

Hopkins, P. (2007), "Oil and gas pipelines: yesterday and today", American Society of Mechanical Engineers, pp. 1-9.

ITA (2008), "Europe pipeline maps", available at: www.theodora.com/pipelines/europe_oil_gas_and_ products_pipelines.html (accessed 15 July 2014).

ITEM SOFTWARE (2014), Fault Tree Analysis, available at: www.reliabilityeducation.com/intro_ft. html (accessed 25 June 2014).

Keifner, J., Maxey, W., Eiber, R. and Duffy, A. (1973), "Progress in flaw growth and fracture testing", Failure Stress Levels of Flaws in Pressurized Cylinders. American Society of Testing and Materials, pp. 461-481.

Kumar, M., Sujata, M., Venkataswamy, M. and Bhaumik, S. (2008), "Failure analysis of a stainless-steel pipeline”, Engineering Failure Analysis, pp. 497-504.

Lau, J. et al. (2004), "Design for lead-free solder joint reliability of high-density packages”, Soldering \& Surface Mount Technology, Vol. 16 No. 1, pp. 12-26.

Leis, B. and Stephens, D. (1997), "An alternative approach to assess the integrity of corroded line pipes", 7th International Offshore and Polar Engineering Conference, Honolulu, HI.

Li, D. (2005), "Multi-attribute decision making models and methods using intuitionistic fuzzy sets", Journal of Computer and System Sciences, pp. 70, 73-85.

$\mathrm{Li}$, D. and Cheng, C. (2002), "New similarity measures of intuitionistic fuzzy sets and application to pattern recognition”, Patter Recognition Letter, Vol. 23 Nos 1-3, pp. 221-225.

Lin, J., Yuan, Y. and Zhang, M. (2014), "Improved FTA methodology and application to subsea pipeline reliability design", PLOS ONE, Vol. 9 No. 3, March.

McLinn, J. (2011), "A short history of reliability”, The Journal of Reliability Analysis Centre, pp. 8-16.

Melchers, R. (1999), Structural Reliability Analysis and Prediction. Chichester, John Wiley \& Sons.

Mon, D. and Cheng, C. (1994), "Fuzzy system reliability analysis for components with different membership functions", Fuzzy Sets and Systems, Vol. 64, pp. 145-157.

Naval Surface Warfare Centre (NSWC) (1998), Handbook of Reliability Prediction Procedures for Mechanical Equipment, Carderock Division: Logistics Engineering Technology Branch.

OMOYA, O. (2013), MACE 64062-Reliability and Maintainability, Manchester.

PHMSA (2014a), All Reported Pipeline Incidents, Washington, DC, PHMSA.

PHMSA (2014b), All Reported Pipeline Incidents by Cause, Washington, DC, PHMSA.

PHMSA (2014c), PHMSA, All Significant Incidents Files: PHMSA.

ReliaSoft Corporation (2003), available at: www.weibull.com/Articles/RelIntro/Brining_It_All_ Together.htm (accessed 15 July 2014).

ReliaSoft Corporation (2005), "Engineering design by reliability”, Reliability Edge, pp. 1-2.

ReliaSoft Corporation (2006), "Fault Tree Analysis, Reliability Block Diagrams and BlockSim FTI Edition”, Reliability Edge, Vol. 4 No. 1. 
IJQRM

36,9

1662
ReliaSoft Corporation (2008a), "Asset performance management supported by reliability engineering”, Reliability Edge, pp. 1-4.

ReliaSoft Corporation (2008b), "Design for reliability: overview of the process and applicable techniques”, Reliability Edge, Vol. 8 No. 2.

Saleh, J. and Marais, K. (2006), "Highlights from the early (and pre-) history of reliability engineering", Reliability Engineering and System Safety, pp. 249-256.

Saravanan, N., Cholairajan, S. and Ramachandran, K. (2008), "Vibration-based fault diagnosis of spur bevel gear box using fuzzy technique”, Expert Systems with Applications.

SCNL (2012), Flowlines and Pipeline Design. Lagos.

Shahriar, A., Sadiq, R. and Tesfamariam, S. (2012), "Risk analysis for oil and gas pipelines: a sustainability assessment approach using fuzzy based bow tie analysis”, Journal of Loss Prevention in the Process Industries, pp. 505-523.

Shalev, D.M. and Tiran, J. (2007), "Condition-Based Fault Tree Analysis (CBFTA): a new method for improved fault tree analysis (FTA), reliability and safety calculations”, Reliability Engineering and System Safety, pp. 1231-1241.

Subsea World news (2013), "Subsea world news", available at: http://subseaworldnews.com/2013/06/ 14/exxonmobil-seeks-contractor-for-offshore-pipelines-project/ (accessed 15 July 2014).

Sun, Y., Ma, L. and Morris, J. (2009), "A practical approach for reliability prediction of pipeline systems”, European Journal of Operational Research, pp. 210-214.

Suresh, P., Babar, A. and Raj, V. (1996), "Uncertainty in fault tree analysis: a fuzzy approach", Fuzzy Sets and Systems, Vol. 83, pp. 135-141.

Uraikul, V., Chan, C. and P.Tontiwachwuthikul (2000), "Development of an expert system for optimizing natural gas pipeline operations”, Expert System Applications, Vol. 18, pp. 271-282.

Walley, P. (1991), Statistical Reasoning with Imprecise Probabilities, London, Chapman Hall.

Walley, P. (1997), "Statistical Inferences based on second order possibility distribution", International Journal of General Systems, Vol. 26, pp. 337-383.

Wyatts (2005), "Reliability block diagram”, available at: http://en.wikipedia.org/wiki/User:Wyatts/ Draft_article_C\#mediaviewer/File:Reliability_block_diagram.png (accessed 20 April 2014).

Yuhua, D. and Datao, Y. (2005), "Estimation of failure probability of oil and gas transmission pipelines by fuzzy fault tree analysis”, Journal of Loss Prevention in the Process Industries, pp. 83-88.

Xie, Y.X. (2007), Research of Risk Assessment Technology for Subsea Oil and Gas Pipeline System, Southwest Petroleum University.

Zhou, J. (2005), "Reliability assessment method for pressure piping containing circumferential defects based on fuzzy probability", International Journal of Pressure Vessels and Piping, pp. 669-678.

Zhou, W. (2010), "System reliability of corroding pipelines", International Journal of Pressure Vessels and Piping, Vol. 87, pp. 587-595.

\section{Corresponding author}

Olanrewaju Ayobami Omoya can be contacted at: olanrewaju.omoya@gmail.com

For instructions on how to order reprints of this article, please visit our website: 